\section{Comparative Analysis of Flexible Stabilization Devices Based on Polymeric and Composite Materials for Degenerative Disorders: Finite Element Analysis}

MoustAFA MOSBAH - Laboratory of numerical and experimental modeling of mechanical phenomena, Department of Mechanical Engineering, University Abd El Hamid Ibn Badis of Mostaganem, Algeria

MoнAmmed BENDOUKHA - Laboratory of numerical and experimental modeling of mechanical phenomena, Department of Mechanical Engineering, University Abd El Hamid Ibn Badis of Mostaganem, Algeria= bendoukham@yahoo.fr

Érkezett: 2018. 06. 01. - Received: 01. 06. 2018. - https://doi.org/10.14382/epitoanyag-jsbcm.2018.27

\section{Abstract}

The radiographic apparent assumed that the asymptomatic adjacent segment disease ASD is common after lumbar fusion, but this does not correlate with the functional outcomes while compensatory increased motion and stresses at the adjacent level of fusion is well-known to be associated to ASD $[4,5,8]$. Newly developed, hybrid and flexible stabilizations are allocated to substitute for mostly the superior level of the fusion in an attempt to reduce the number of fusion levels and likelihood of degeneration process at the adjacent levels during the fusion with pedicle screws. Nevertheless, its biomechanical efficiencies still remain unknown and the complications associated with failure of constructs such screw loosening and toggling should be elucidated [4]. In the current study, a finite element (FE) study was performed using a validated L2/S1 model subjected to a moment of $10 \mathrm{Nm}$ and follower load of $100 \mathrm{~N}$ to assess the biomedical behavior of hybrid constructs based on dynamic topping off, semi-rigid fusion using polymeric and composite materials.

Keywords: adjacent segment disease, fusion, degeneration, finite element, hybrid constructs, dynamic topping off, semi-rigid

\section{Introduction}

Lumbar fusion is considered as the "gold standard" surgical treatment indicated for a wide range of well-recognized painful conditions $[1,8,11]$. Which aimed to alleviate and treat the pain from disc/facet loading in the instable degenerated levels, probably cause of the abnormal load share and stresses in lumbar spine $[8,12]$, while the surgical intervention is based on the topping off fusion stabilization, we used a validated Finite Element (FE) Model to determine the biomechanical basis exists for believing that the reduced stiffness and increased axial motion conferred by dynamic instrumentation using mobile and fixed screw implants to alter the stresses in adjacent-level discs [8,11]. Conventionally, the Posterior Dynamic Stabilization PDS constructs has been promoted to be used as a total fixation system [5] or joined to spinal fusion (topping off or bottoming off fusion) of various rigid or semi rigid fixators assumed to diminish the load on adjacent disc and the facet joint $[3,6,9]$. It will be used in treating multilevel spinal degeneration requiring surgical procedure by strengthening their arthrodesis (fusion) at one or more levels and neutral stabilization (non-fusion) at an adjacent level for common pathological condition to limit stress prophylactically at the level above or below the fusion.

\section{Methods and materials}

The L2/S1 spine model was adopted from the previously validated nonlinear finite element (FE) model L1/S1 [19], and computationally established to simulate instability by discectomy and quantify implant stability as a function of implant/bone quality. The mesh was developed using ANSYS version 15 (Swanson Analysis System) and Hypermesh 13.0 (Altair Engineering. Inc). Model was subjected to combined compression load to flexion, extension moment of $10 \mathrm{Nm}$, the axial compressive load of $100 \mathrm{~N}$ was applied as a follower load to follow the motion of the spine [10]. Utmost component geometry of the spine was originally taken from Computer Tomography images. The detailed bone anatomy of the spine: vertebrae, endplates, bone processes, and facet joints were defined using 8-node Hex element [3, 8, 18]. Generally; the IVD composed three highly specialized structures the Annulus Fibrosis (AF), The Nucleus Pulposus (NP), and the cartilage endplate that form the interface with the adjacent vertebral bodies. The Nucleus pulposus NP occupies 30 50\% volume of the IVD according to Chen et al [1] and the annulus has several layers. For saving time from creating several IVDs, the annulus fiber layers are simplified to the inner and the outer laminates. The IVD boundary curve is already done in previous validation process [19]. The seven major ligaments, including anterior Longitudinal Ligament ALL; Posterior Longitudinal Ligament PLL; Intertransverse Ligament ITL; Ligamentum 
Flavum LF; Capsular Ligament CL; Supraspinous Ligament SSL; and Interspinous Ligament ISL were modeled as three dimensional, 2 noded truss elements (T3D2) and allocated nonlinear hypoelastic behavior $[5,11,3]$.

The cross section areas of ligaments are separated into several trusses for avoiding the constraint of stress. The entire model consists of approximately 115000 C3D8 element and 128000 nodes and 465516 DOF. The annulus rebar reinforced layer is meshed in isotropic quads, and each quad shell element has its local orientation axes. The isotropic mesh benefits all first axes parallel with the endplate, facilitate defining the material orientation. The collagenous fibers lamellae were defined as fiber-reinforced concentric rings including embedded bands of reinforced collagenous fibers defined as rebar element surrounded the nucleus pulpous [14]. These Fibers elements were oriented at approximately $( \pm 30)$ into one layer. The Nuclei Pulposi (NP) was modeled as hydrostatic fluid elements $[9,13]$. The facet joints simulated by a cartilaginous layer of thickness of $0.4 \mathrm{~mm}$ were modeled to be multi-linear elastic in compression [8] by surfaces-to surface contact with softened contact in the normal direction with a coefficient of 0.1 [13, 14] An initial typically gap of $0.2 \mathrm{~mm}$ was specified as reported $[8,19]$.

\begin{tabular}{|c|c|c|c|c|}
\hline Bony structures & \multicolumn{2}{|c|}{$\begin{array}{c}\text { Young's modulus } \\
\text { E (MPa) }\end{array}$} & $\begin{array}{l}\text { Poisson's } \\
\text { ratio } v\end{array}$ & Reference \\
\hline Concellous bone & \multicolumn{2}{|c|}{100} & 0.2 & \\
\hline Cortical bone & \multicolumn{2}{|c|}{12,000} & 0.3 & {$[3,5,18]$} \\
\hline Posterior Process & \multicolumn{2}{|c|}{3,500} & 0.25 & \\
\hline Cartilaginous End plate & \multicolumn{2}{|c|}{23.8} & 0.4 & {$[15,16]$} \\
\hline Facet cartilage & \multicolumn{2}{|c|}{11} & 0.4 & \\
\hline Facet contact & \multicolumn{3}{|c|}{ Nonlinear soft contact } & {$[5,13]$} \\
\hline Annulus Ground & \multicolumn{3}{|c|}{ incompressible fluid } & {$[13]$} \\
\hline Nucleus Pulposus & \multicolumn{2}{|c|}{4.2} & 0.45 & {$[2,3]$} \\
\hline Annulus fibers & \multicolumn{2}{|c|}{175} & 0.3 & {$[3]$} \\
\hline Major Ligaments & $E(\mathrm{MPa})$ & $\begin{array}{l}\text { Strain } \\
\text { transition }\end{array}$ & $\begin{array}{c}\text { Cross- } \\
\text { Sectional } \\
\text { Area } \\
\left(\mathrm{mm}^{2}\right)\end{array}$ & Reference \\
\hline ALL & $7.8-20$ & $12 \%$ & 63.7 & \\
\hline PLL & $10-20$ & $11 \%$ & 20 & \\
\hline LF & $15-19$ & $6.2 \%$ & 40 & \\
\hline CL & $7.5-33$ & $25 \%$ & 30 & {$[2,3]$} \\
\hline ITL & $10-59$ & $18 \%$ & 1.8 & \\
\hline ISL & $10-12$ & $14 \%$ & 40 & \\
\hline SSL & $8-15$ & $20 \%$ & 30 & \\
\hline $\begin{aligned} \text { Table.1. } & \text { Material properti } \\
\text { 1. táblázat } & \text { Az L2/S1 lumbos } \\
& \text { anyagjellemzök }\end{aligned}$ & $\begin{array}{l}\text { ies used in the } \\
\text { szakrális gerin }\end{array}$ & $\begin{array}{l}\text { FE-Model of } l \\
\text { c végeselemes }\end{array}$ & $\begin{array}{l}\text { umbosacral spir } \\
\text { modelljében has }\end{array}$ & $\begin{array}{l}\text { L } L / S 1 \\
\text { nált }\end{array}$ \\
\hline
\end{tabular}

\section{Implant placements}

The instable post-operative segments was modeled using polymeric materials (PolyEtherEtherKetone PEEK, PET PolyEthylene Terephthalate, Poly

Carbonate Urethan PCU) and carbon reinforce composite material (ostaPek) in six different configurations of the model by:
Fusion model is shown in Fig. 1: two 5.5-mm PEEK rods or two 5.5-mm ostaPek rods and one PEEK spacer were added through placing them along the L3/L4 segments without distraction. All pedicle screws were rigidly fixed to the vertebrae.

The topping off fusion assembly was simulated using pedicle screw based PEEK or ostaPek Fusion with Supra adjacent level PEEK (Fig. 1) or OstaPek Rods.

Topping off fusion using Hybrid Dynesys DTO systems, DynaPEEK and DynostaPek constructs.

\begin{tabular}{lcccc}
\multicolumn{1}{c}{$\begin{array}{c}\text { Implants } \\
\text { Component }\end{array}$} & E (MPa) & $\begin{array}{c}\text { Poisson's } \\
\text { ratio v }\end{array}$ & $\begin{array}{c}\text { Pretension } \\
\text { (N) }\end{array}$ & Reference \\
$\begin{array}{l}\text { Pedicular screws } \\
\text { (all models) }\end{array}$ & 110.000 & 0.3 & - & {$[16]$} \\
$\begin{array}{l}\text { PEEK rods } \\
\text { ostaPek rods }\end{array}$ & 3,500 & 0.4 & - & {$[17]$} \\
$\begin{array}{l}\text { PCU Spacers } \\
\text { (all models) }\end{array}$ & 45000 & 0.4 & - & {$[21]$} \\
300 N Pretention & 62.5 & 0.4 & - & {$[16]$} \\
Cord & 1500 & 0.4 & 300 & {$[16]$} \\
& & & & \\
Table 2. Material properties used in the implant \\
2. táblázat. Az implantátumban használt anyagjellemzök
\end{tabular}

The ostaPek composite is composed of long carbon fibers (66.6\%) and a PEKEKK (PolyEtherKetoneEtherKetoneKetone) matrix (33.3\%) designed to stable construct, and improves the patient's possibilities to create a viable, stable and definitive fusion and provide high strength of metals combined with the biocompatibility and imaging advantages of polymers. ostaPek composite provides the necessary stiffness to achieve stabilization, combined with the desired flexibility to prevent stress shielding (Fig. 1).

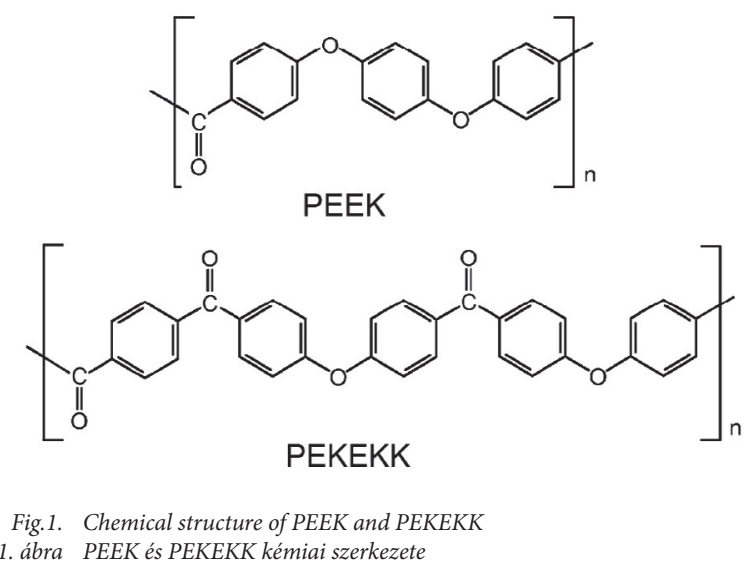

The novel implant for the Dynesys + Fusion (DTO) model consisted of six titanium alloy screws (diameter: $6.4 \mathrm{~mm}$, length: $45 \mathrm{~mm}$ ) and using PEEK or OstaPek rod instead of Titanium Ti rod Moreover, two PCU spacers (Diameter: 12 mm, Length: $30 \mathrm{~mm}$ ) and $300 \mathrm{~N}$ pretention PET cord, which contacted the screw in Dynesys model [16]. The intact model was modified to simulate the instability caused by a discectomy, which modeled by removing some part of the annulus from the anterior side of the disc [17] that produces natural physiological spinal motions (Fig. 2). The cage was simulated in the fused level attempting to restore the lumbar lordosis during surgery. 


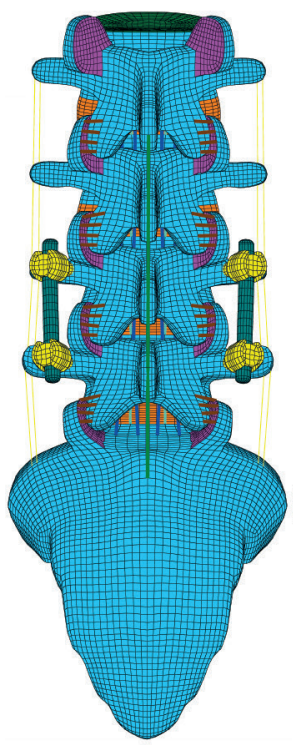

(a)

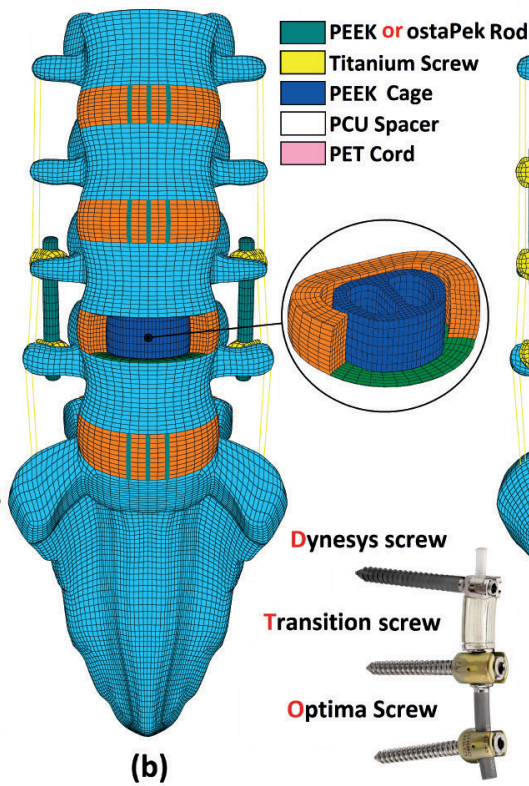

(b)

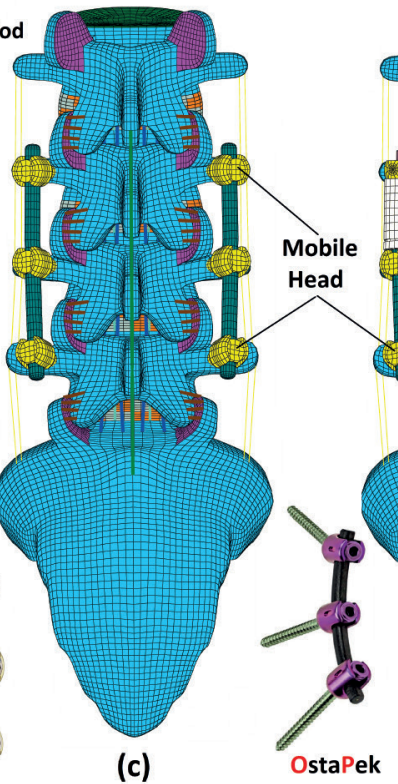

(c)

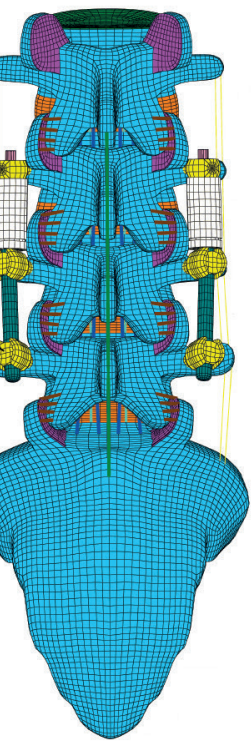

(d)

Fig. 2. FE-Model of the lumbosacral spine after posterior hybrid surgery: (a) Intact, (b) PEEK or OstaPek Fusion, (c) BiPEEK or BiostaPek, (d) DTO: DynaPEEK or DynostaPek (DTO)

2. ábra Lumboszakrális gerinc végeselemes modellje posterior hibrid mütét után: (a) ép, (b) PEEK vagy OstaPek fúzió, (c) BiPEEK vagy BiostaPek, (d) DTO: DynaPEEK vagy DynostaPek (DTO)

\section{Results}

\subsection{Intersegmental rotation}

The results indicate that the free (unfused) intervertebral level is subjected to additional stresses and acquires increasing motions overtime (Fig. 3). Therehave been severalbiomechanical studies attempting to document changes in spine due to simulated fusion. Hypermotion in flexion was predicted after PEEK or ostaPek fusion by $10 \sim 16 \%$ in L2/3 and L3/4 and about $43 \sim 55 \%$ in L2/3 and L3/4 in extension. The reduction of ROM following hybrid instrumentation is shown in Fig. 3. Following discectomy, L3/4 extension ROM decreased by 63\% for PEEK and ostaPek fusion and 57\% for DynaPEEK and DynostaPek. Stabilizing these segments with DTO controlled that ROM to $70 \%$ versus that of an intact segment. Adding PEEK fusion and Dynesys systems is sufficient to stabilize the corresponding L3/4 ROM while preserving more than $32 \sim 28 \%$ of its intact flexion. DTO systems allows displacement while eliminating screw loads in the topping of fusion level, a major source of the screw toggling and loosening. The OstaPek rod, due to its bending flexibility, reduces the ROM comparing to PEEK system. At the fused segment (L2/3), all hybrid implants had the same stabilizing effect by reducing the angular motion by $86 \%$ compared to the intact spine. The fusion induced increased motion at the adjacent segment (L3/4) while the bilevel stabilization BiPEEK reduced potentially the motion. While the Bilevel BiostaPek Preserve motion in the adjacent level $\mathrm{L} 2 / 3$ in flexion/extension by $95 \sim 99 \%$ of rotation and strength the arthrodesis by reducing the mobility in the topping off fusion level L3/4 by 35 39\% versus that of an intact

\subsection{The intradiscal pressure}

At adjacent level L2/3 in the PEEK Fusion model is slightly higher than the intact model for flexion (about $328 \mathrm{KPa}$ and $165 \mathrm{KPa}$ ) (Fig.4). In contrast, it is affected by DTO implant which is slightly lower (186 KPa). 
The pressure reduction in extension is even more pronounced for hybrid solution, however the IDP of bilevel stabilization increases to a level of about $37 \%$ compared to the fusion model. In contrast, hybrid implant decreases the pressure in the adjacent disc L2/3 about 79 86\%.

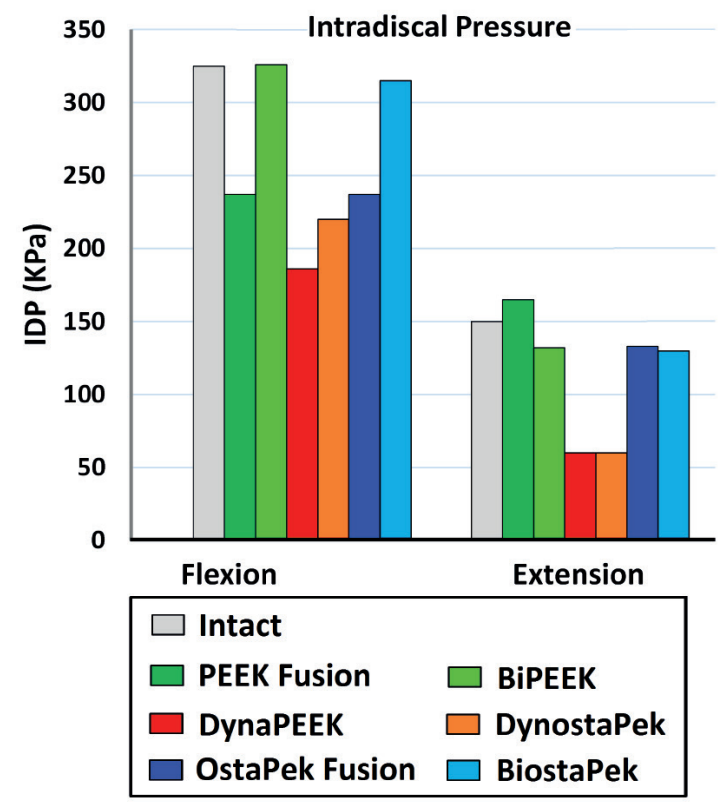

Fig.4. Intradiscal pressure IDP at the L2/L3 level for the intact, Polymeric and composites constructs under Flexion-Extension

4. ábra Intradiszkális nyomás az L2/L3 szinten - ép, polimer és kompozit szerkezet hajlitás és megnyúlás hatására

\subsection{Stress results}

As it is predicted; the hybrid systems are highly stressed, while the rest of the structure's motion is preserved (Fig. 5).

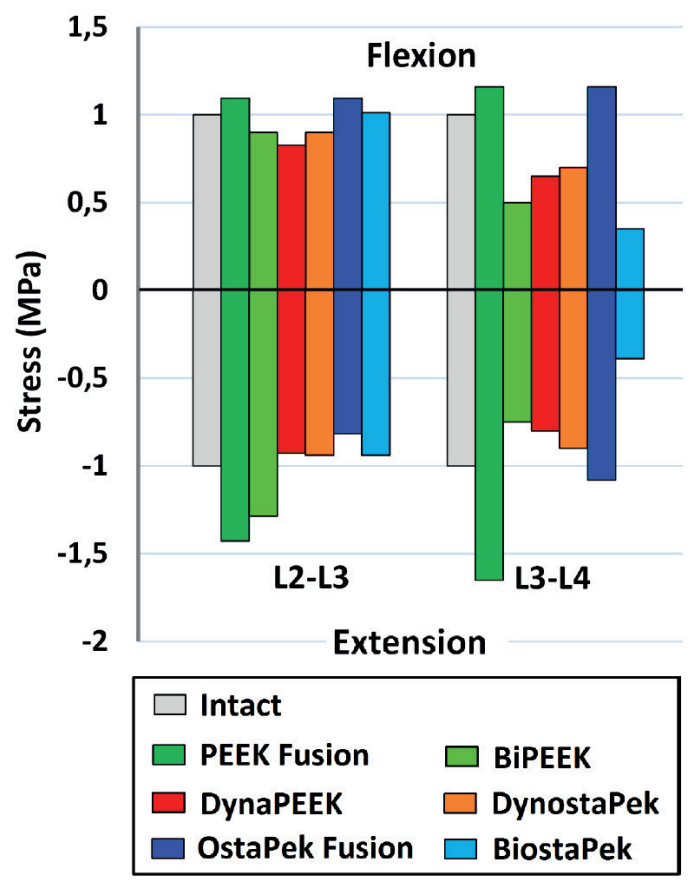

Fig 5. Von Mises Stress distribution in the Annulus of L3/L4 level for various scenarios under flexion and extension

5. ábra Von-Mises feszültségeloszlás az L3/L4 szint gyưrüjén eltérő hajlitás és megnyúlás hatására
Principal stresses in the intervertebral disc specify that, the nucleus pulposus is always induced in compression; with fusion the tensions were higher at the periphery of the Annulus for both flexion and extension, as predicted that the decrease of stresses was accompanied by an increase of shear strain.

\section{Discussion}

The treatment outcome using hybrid constructs was relatively satisfactory [2]. A PDS topping off semi-rigid fusion system was optimized with a stiffness equivalent to that of an intact spinal segment is sufficient to stabilize the spine while preserving $60 \%$ of its intact ROM, Consequently reducing the load on its structural element. Dynesys and ostaPek rods reduced most of segment $\mathrm{ROM}$, as well as strengthening as fusion devices. Semi-rigid Fusion PEEK Fusion alters the kinematics in the adjacent segment by redistributing the range of motion and leads to increase tension in the disc's fibers. The fusion surgery of the spine is accomplished by stimulating bone to grow between two or more adjacent spinal segments to prevent future motion. The instrumentation used in flexible stabilization is designed to control the amount of motion between adjacent vertebrae, but it does not completely eliminate this movement, preventing degenerative changes in the adjacent segments, and reducing instrument failures such screw toggling and loosening. Flexible stabilization for fusion technology support for better physiological bony fusion without shielding the stress. As such, the system is adaptable to the various stages of disc degeneration from early degenerative stage of intervertebral disc to ultimate stage of disc degeneration requiring a fusion. This level of flexibility (PEEK ostaPek) not only offers spine surgeons more options in the treatment of lumbar disc diseases.

The tensile strength, stiffness makes the constructs ideal as a metal replacement in spinal implants. It provides the high strength of conventional systems and at the same time increases the flexibility to allow load-sharing while still protecting against pathological displacements.By choosing a strength and stiffness closely matches that of cortical bone, PEEK Polymer and ostaPek composite are employed in spinal applications in order to avoid stress shielding and result a transition bridge from the fused to the unfused level

\section{Significance}

The current FE investigation suggested that substitution of the superior level fusion with the adjunct PDS devices in multi-level fusion procedures may be able to offer similar biomechanical outcome and stability while reducing likelihood of ASD and the feasibility of a PDS adjunct combined to fusion implant system that provides increased load sharing with the construct addressing the Lumbar stenosis, facet pain and the disc degeneration. This avoids the PDS material stress shielding compared to non-dynamic design iterations. Non fusion techniques are newly innovated compared to fusion, as an option in the surgical treatment for low back pain. As new techniques, long term prospective studies must be designed to achieve their effectiveness. 


\section{Limitations}

Our FE study certain limitations. Firstly, The Nucleus was modeled with a fluid filled cavity without considering its continuum structure, muscle forces and loads were not simulated in the current study. The muscle contractions may carry complicated external forces that have significant influences on the biomechanical viewpoint [9]. The above factors will be considered in our further study. Although there were certain simplifications in our FE model, the FE model was well validated previously. Consequently, the L1/S1 model modified in this study is reasonable and can be used as an effective tool to assess the effects of three stabilization systems on the lumbosacral spine. In all the placement cases, there was no incidence of abnormal high stress concentration that could lead to the implant failure.

\section{References:}

[1] Chen, H. - Charles, Y. P. - Bogorin I. - Steib J. P. (2011): Influence of 2 different dynamic stabilization systems on sagittal spinopelvic alignment. Journal of spinal disorders \& techniques.2011; 24(1):37-43.

[2] Denoziere, G. - Ku, D. N. (2006): Biomechanical comparison between fusion of two vertebrae and implantation of an artificial intervertebral disc, Journal of Biomechanics, 39(4), 766-775.

[3] Goel, V. K. - Monroe, B. T. - Gilbertson, L. G. - Brinckmann, P. (1995): Interlaminar shear stresses and laminae separation in the disc. Finite element analysis of the L3-L4 motion segment subjected to axial compressive loads. Spine, 20(6), 689-698.

[4] Kashkoush, A. - Agarwal, N. - Paschel, E. - Goldschmidt, E. - Gerszten P. C. (2016): Evaluation of a Hybrid Dynamic Stabilization and Fusion System in the Lumbar Spine: A 10 Year Experience. Cureus. 2016 Jun 10;8(6):e637. https://doi.org/10.7759/cureus.637

[5] Lee, S. E. - Jahng, T. A. - Kim, H. J. (2015): Hybrid surgery combined with dynamic stabilization system and fusion for the multilevel degenerative disease of the lumbosacral spine. International Journal of Spine Surgery. 2015, 9:45. https://doi.org/10.14444/2045

[6] Marion, P. H. - Barrios, C. - Rouch, P. - Charles, Y. P. - Steib, J. P. - Skalli, W. (2015): Clinical Outcomes and Complications After Pedicle-anchored Dynamic or Hybrid Lumbar Spine Stabilization: A Systematic Literature Review. Journal of Spinal Disorders \& Techniques 2015 Oct;28(8):E439-48

[7] Maserati, M. B. - Tormenti, M. J. - Panczykowski, D. M. - Bonfield, C. M. - Gerszten, P. C. (2010): The use of a hybrid dynamic stabilization and fusion system in the lumbar spine: preliminary experience. Neurosurgical focus. 2010;28(6):E2.

[8] Moumene, M. - Geisler, F. H. (2007): Comparison of biomechanical function at ideal and varied surgical placement for two lumbar artificial disc implant designs: mobile-core versus fixed-core. Spine. 32:1840-1851. https://doi.org/10.1097/BRS.0b013e31811ec29c
[9] Paige, L. J. (2004): Finite element modeling of annular lesions in the lumbar intervertebral disc. (Doctoral Thesis).

[10] Patwardhan, A. G. (1999): A Follower Load Increases the Load-Carrying Capacity of the Lumbar Spine in Compression. Spine, 24(10), 1003 (1999).

[11] Prasath, M. - Fernando, T. - Robb, W. C. - Tara, F. B. - Robert, F. M. (2012): Hybrid dynamic stabilization: a biomechanical assessment of adjacent and supra adjacent levels of the lumbar spine Laboratory investigation, Spine, 2012. https://doi.org/10.3171/2012.6.SPINE111054

[12] Rahm, M. D. - Hall, B. B. (1996): Adjacent-segment degeneration after lumbar fusion with instrumentation: a retrospective study. Journal of Spinal Disorders 1996;9:392-400.

[13] Rohlmann, A. - Zander, T. - Schmidt, H. - Wilke, H-J. - Bergmann, G. (2006): Analysis of the influence of disc degeneration on the mechanical behaviour of a lumbar motion segment using the finite element method. Journal of Biomechanics 39:2484-2490. https://doi.org/10.1016/j.jbiomech.2005.07.026

[14] Schmidt, H. - Heuer, F. - Simon, U. - Kettler, A. - Rohlmann, A. Claes, L. (2006): Application of a new calibration method for a threedimensional finite element model of a human lumbar annulus fibrosus, Clinical Biomechanics, 2006, 21, 337-344.

[15] Sharma, M. - Langrana, N. A. - Rodríguez, J. (1995): Role of ligaments and facets in lumbar spinal stability. Spine. 1995; 20:887-900.

[16] Shih, S. L. - Liu, C. L. - Huang, L. Y. - Huang, C. H. - Chen, C. S. (2013): Effects of cord pretension and stiffness of the Dynesys system spacer on the biomechanics of spinal decompression- a finite element study. $B M C$ Musculoskeletal Disorders 2013 19; 14:191. Epub 2013 Jun 19.

[17] Tsuang, Y. H. - Chiang, Y. F. - Hung, C. Y. - Wei, H. W. - Huang, C. H. - Cheng, C. K. (2009): Comparison of cage application modality in posterior lumbar interbody fusion with posterior instrumentation-A finite element study. Medical Engineering \& Physics 31 (2009) 565-570

[18] Zhong, Z. C. - Wei, S. H. - Wang, J. P.. - Feng, C. K.. - Chen, C. S. - Yu, C. H. (2006): Finite element analysis of the lumbar spine with a new cage using a topology optimization method, Medical Engineering and Physics, 28(1), 90-98.

[19] Bendoukha, M. - Mosbah, M. (2017): Biomechanical Evaluation of Lumbosacral Segments Response under Physiological Functions: Finite Element Analysis, Épitöanyag - Journal of Silicate Based and Composite Materials, Vol. 69, No. 3 (2017), 122-126. p. https://doi.org/10.14382/epitoanyag-jsbcm.2017.22

[20] Abaqus Analysis 6.10 User's Manual

[21] Benzel, E. (2001): Biomechanics of Spine Stabilization, Stuttgart: Thieme 2001; pp $19-221$

Ref::

Mosbah, Moustafa - Bendoukha, Mohammed: Comparative Analysis of Flexible Stabilization Devices Based on Polymeric and Composite Materials for Degenerative Disorders: Finite Element Analysis Építőanyag - Journal of Silicate Based and Composite Materials, Vol. 70, No. 5 (2018), 146-150. p.

https://doi.org/10.14382/epitoanyag-jsbcm.2018.27

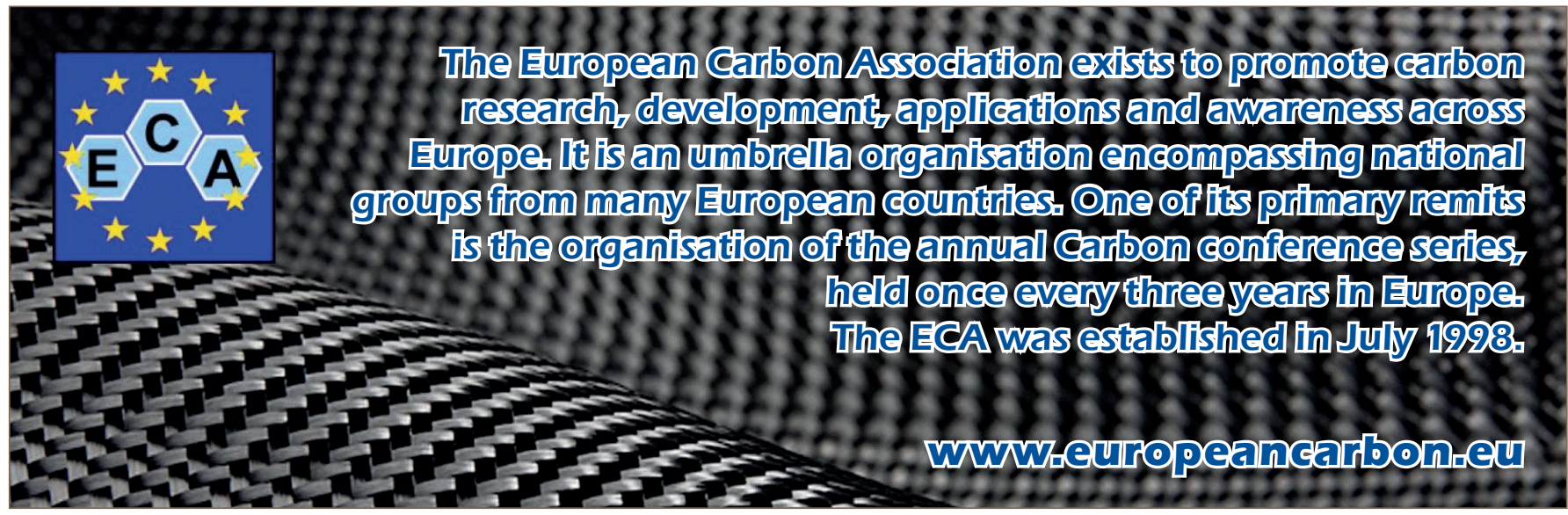

